\title{
Estados Nacionales Y Víctimas Sacrificiales: Consideraciones Sobre El Genocidio Maya-Ixil En Guatemala
}

\author{
Eliana Cárdenas Méndez (Doctora) \\ Universidad de Quintana Roo, México
}

Doi:10.19044/esj.2018.v14n20p121 URL:http://dx.doi.org/10.19044/esj.2018.v14n20p121

\begin{abstract}
"Tierra Arrasada" (Scorched Earth) was a military program applied in Guatemala by former President José Efraín Ríos Montt, against Mayan communities accused of collaborating with the guerrilla force, and had the aggravating elements of a genocidal campaign. The guiding question of this essay is: "What is the reason for the genocides against ancestral peoples?", and has the following starting hypothesis: the modern nation states, as "imagined communities", contain an inherent "bio-racial" component which gives sense and structure to the power instrumentation. Racism is recognized as a root element in Guatemalan history and, together with socioeconomic and political factors, has led to the genocide of Ixil people. Following René Girard, this paper proposes that Ixils were "sacrificial victims" in the contest for power between the Guatemalan State and the Ejército Guerrillero de los Pobres (EGP) in order to sustain the hegemonic power with low political and military costs. Methodologically it is the results of field studies among communities of former Guatemalan refugees in Quintana Roo, Mexico, as well as historical and discourse analysis. The aim of this paper is to present the semantic potential of a theory of mimetics for the study of genocides in modern states.
\end{abstract}

Keywords: Internal enemy, ixil genocide, sacrificial victims.

\section{Resumen}

El programa militar "Tierra Arrasada", implementado por el expresidente José Efraín Ríos Montt en Guatemala contra las comunidades indígenas mayas bajo el supuesto de colaborar con la guerrilla, contiene los agravantes de una campaña genocida. La pregunta ordenadora de este ensayo es: ¿cuál es la razón de los genocidios contra pueblos ancestrales?, y parte de la siguiente hipótesis: los Estados nacionales modernos, en tanto "comunidades imaginadas", contienen un componente bio-racial intrínseco 
que da sentido y estructura la instrumentalización del poder. Reconoce el racismo como un elemento de raigambre en la historia de Guatemala que, junto con factores socioeconómicos y políticos, desembocó en el genocidio contra el pueblo ixil. Siguiendo a René Girard propone que los ixiles fueron "víctimas sacrificiales" en el marco de la contienda por el poder entre el Estado guatemalteco y el Ejército Guerrillero de los Pobres (EGP) para sostenimiento del poder hegemónico, con bajos costos políticos y militares. Metodológicamente, es resultado de trabajo de campo entre las comunidades de ex refugiados guatemaltecos en Quintana Roo, México, y el análisis histórico y de discurso. Su objetivo radica en presentar el potencial semántico de la teoría mimética para el estudio de los genocidios en los Estados modernos

Palabras clave: Enemigo interno, genocidio ixil, víctimas sacrificiales.

¡Adelante, continúen aniquilando esta raza!

[...] ¡Miren si pueden hacerlo! ¡Sáquenlos de sus casas y envíenlos a la selva!

¡Déjenlos sin comida!

Quemen sus casas e iglesias Pero luego, miren si son capaces

De volver a reír.

(Paráfrasis del poema Armenia, de William Saroyan)

\section{Introducción}

La guerra civil en Guatemala hunde sus raíces en el derrocamiento del presidente Jacobo Árbenz, líder moderado que incluía en el desarrollo para Guatemala una reforma agraria que amenazaba los latifundios de la United Fruit Company. En 1954 es depuesto por un golpe de Estado dirigido desde Estados Unidos de América (EUA), que lo sustituyó por una Junta Militar.

A partir de ahí, el país vivió alternancias presidenciales por elección popular y otras de facto, pero siempre marcado por la violencia de Estado contra cualquier expresión de alternancia política. La historia oficial reconoce el periodo 1960-1996 como lapso donde se llevó a cabo una guerra civil, que, según el Informe de la Comisión para el Esclarecimiento Histórico, dejó un saldo de 200,000 víctimas mortales, 45,000 desaparecidos, un millón de desplazados, más de 600 masacres y 400 aldeas destruidas. La mayoría eran civiles desarmados, sobre todo indígenas mayas, que representaron $83 \%$ de las víctimas aunque su presencia en la población es 59\%, y 17\% eran ladinos.

La sucesión histórica de la guerra presenta a los gobiernos de Fernando Romeo Lucas García (1978-1982) y Ríos Montt (1978-1983) como periodos donde se vivieron los momentos más violentos del país, en una contienda que 
enfrentó a grupos de derecha, financiados por EUA contra una guerrilla comunista.

Durante el gobierno de Ríos Montt se ejecutó el programa político militar "Tierra Arrasada", estrategia fundada en una antípoda de la premisa de Mao Tse-Tung: las poblaciones son a la guerrilla, lo que el agua es al pez. Por tanto, la proclama del ex dictador se basó en quitarle el agua al pez. Durante ese periodo, el Ejército de Guatemala llevó a cabo ataques contra poblaciones acusadas de colaborar con las diferentes organizaciones guerrilleras.

Una zona muy golpeada fue el "Triángulo Ixil", que comprende los municipios de Nebaj, San Juan Cotzal y San Gaspar Chajul, departamento Quiché, asentamiento del grupo maya-ixil. Los planes militares contra los ixiles fueron referenciados durante el juicio porque incluyeron masacres, desplazamientos, ejecuciones, desapariciones, violaciones de mujeres, tortura, traslado de niños, reclutamientos, privación de suministros, bombardeos y quema de cosechas y aldeas. Dichas atrocidades se saldaron con más de 29,000 ixiles desplazados y 1,771 asesinatos en 15 de las 626 masacres documentadas (Comisión para el Esclarecimiento Histórico, 1994).

En razón de estos agravantes, de acuerdo con el Derecho Internacional, se implementó una política genocida. Así, el 19 de marzo de 2013 inició el juicio contra Ríos Montt y José Mauricio Rodríguez Sánchez, jefe del servicio de inteligencia durante su mandato, por los delitos de genocidio y crímenes de lesa humanidad.

Ríos Montt fue condenado a ochenta años de prisión; cincuenta inconmutables por delito de genocidio. También, fue hallado culpable por delitos de incumplimiento de deberes de humanidad, por lo cual recibió una condena de treinta años, igualmente inconmutables, convirtiéndose así en el primer mandatario en América Latina en ser llevado a juicio por estos delitos. Sin embargo, la justicia en Guatemala sufrió un duro revés cuando la Corte de Constitucionalidad de Guatemala determinó que el juicio y la sentencia quedaban sin efecto por razones de procedimiento.

El genocidio es un caso de justicia sin resolver y en la academia un tema abierto. Por ello, son precisos algunos señalamientos para abonar en la comprensión de los genocidios en el marco de los Estados-nacionales.

La definición misma de genocidio y la tipificación de acciones que lo conforman no aclaran en qué circunstancias se comete. Dado que se establece en los marcos jurídicos, recae sobre una persona o responsables directos en un encadenamiento de mandos, razón por la que se invisibiliza como estrategia efectuada desde el poder hegemónico, así como la gestión, burocratización e instrumentalización de la muerte decretada contra un colectivo. Aunque las víctimas de genocidio son más fáciles de reconocer, los móviles por los cuales las poblaciones se convierten en objetivos militares son de tal magnitud que el término adquiere plasticidad, lo que exige, en cada caso, precisiones analíticas 
para operacionalizarlo; es necesario indicar si los colectivos fueron victimizados por razones políticas, religiosas, identitarias, nacionales o raciales.

Son los casos de los genocidios argentino, armenio, kurdo judío y tutsi. Aunque todos tienen un componente político-cultural, no todos tienen el racial. Sin embargo, en nuestro razonamiento, el racismo es el principal móvil de los genocidios en la modernidad, y se articula a la construcción imaginaria de nación, como intentaremos demostrar más adelante.

¿Por qué esta saña contra pueblos ancestrales? La pregunta nos interpela desde un principio, pero su respuesta requiere el concurso de muchas disciplinas. Nos esforzaremos, pues, en responder una menos ambiciosa y con enfoque etnohistórico: ¿por qué las comunidades mayas-ixil se convirtieron en objeto de exterminio en una nación moderna?

Partimos de la hipótesis de que los Estados modernos son proclives a los genocidios en razón de su anclaje étnico-racial. La homogenización racial y cultural, ideal de las comunidades nacionales, explica en gran medida el genocidio en Guatemala.

Desestimamos la idea, muy socorrida en la literatura sobre los atroces acontecimientos contra las comunidades mayas, de que sean identificadas como "enemigo interno."

Hemos privilegiado, en razón de la primera hipótesis, que el genocidio se verificó en el entrecruzamiento entre ideologías políticas y estrategias militares (Estado y guerrillas) en territorios de una población que, en el discurso hegemónico, era sacrificable en razón del fenotipo racial. Vidas desechables a efectos de implementar un castigo ejemplar para escarmiento de la población, a fin de debilitar apoyos a la guerrilla. En la contienda se desnuda el imaginario colectivo de la sociedad guatemalteca, en que las comunidades ancestrales se representan como lastre para el desarrollo y culpables de las crisis de donde los "enemigos internos" obtienen su fuerza para oponerse al poder hegemónico.

En la lucha por el poder contra organizaciones de izquierda, se trasmutan en víctimas sacrificiales; su inmolación, en razón del racismo arraigado en la sociedad guatemalteca, las convertían en "víctima propiciatoria", a la cual el Estado podría recurrir para a vencer a sus enemigos directos. Este carácter de víctimas propiciatorias ("quitarle el agua al pez") resulta de la cristalización de constructos imaginarios que evitó el enfrentamiento entre contendientes directos (Estado-Ejército Guerrillero de los Pobres) y lo desplazó hacia una población previamente despojada, en razón del racismo, del primer reconocimiento y dignidad: el de seres humanos. El racismo es la mueca obscena de la barbarie inscrita en el genocidio de Guatemala. 


\section{Tierra arrasada: víctimas propiciatorias y el terror como pedagogía}

Es preciso un discernimiento previo: ¿cuál es la diferencia entre enemigo y víctima propiciatoria? La etimología considera 'enemigo' a toda persona o grupo que se opone a otra en sus ideas o actividades; contrario a 'adversario', con quien se puede negociar, pues no tiene como objetivo la conquista de poder o territorios.

El enemigo es expresión de antagonismo movilizado en una lucha de intereses por el alcance de los mismos beneficios. La solución entre enemigos es la muerte, real o simbólica, porque sólo uno puede vencer. Lo cierto es que los enemigos se construyen imaginaria e ideológicamente, de tal suerte que la fricción tiene un desenlace político o militar. Esto es claro bajo el concepto "enemigo interno", que se construyó para intervenir los procesos sociales de alternancia política en América Latina.

La "otredad", en cambio, no es enemigo ni adversario; es el otro que, en su radical diferencia, reafirma nuestra identidad. Así, es posible establecer los rayanos entre los "unos," (no indígenas, constituidos por grupos dominantes) y los "otros" (indígenas, dominados). En esta interacción, este otro-dominado se presenta agotado en su realidad, prescindible, sujeto de exterminio.

El genocidio tiene anclaje en esta perspectiva: es el "otro", como diferencia despojada de humanidad, convertido en víctima propiciatoria para sofocar la guerra entre enemigos.

La prioridad en las masacres hacia los pueblos indígenas, en modo alguno era una estrategia para apaciguar su peligrosidad. Era lo contrario: su vulnerabilidad fue un elemento que alentó la dimensión del oprobio, a diferencia de los enemigos comunistas, con objetivos contrarios al ideario de nación. El racismo contra los mayas los despoja de contenido, ni siquiera alcanzan estatus de enemigos. Son carga contra el progreso.

$\mathrm{Si}$ sostenemos que las sociedades modernas recurren al exterminio en contiendas políticas, semejantes a prácticas rituales sacrificiales como las realizadas en contextos religiosos de la antigüedad: ¿cuál es la diferencia? Según René Girard (1995), las sociedades religiosas recurren a la violencia sacrificial y la desplazan hacia una víctima de recambio a fin de mantener la cohesión del grupo para desviar la violencia entre contendientes directos. Adicionalmente, enseña que las características de las víctimas sacrificiales tienen como condición que sean vulnerables y que nadie quiera resarcir su muerte, por tanto, extinguen la venganza, combustible de toda violencia.

Las sociedades modernas, cuyo correlato son los nacionalismos y la idea de una comunidad integrada entre iguales, se encuentran siempre con grupos marcados por diferencias raciales y culturales, a quienes han querido integrar a la nación vía el exterminio de sus prácticas sociales y culturales, a fin de que se asemeje al modelo ideal. 
Han sido intentos fracasados, en general, ya sea porque nunca se ha mostrado un procesos decidido de integración, caso de Guatemala, cuyas poblaciones indígenas han permanecido siempre en la marginalidad; o bien, por la resistencia cultural de estos pueblos.

Así, en tiempos de crisis, los grupos étnicos se convierten en banco de reserva de víctimas para el desahogo de apremios de cualquier índole que amenace la estructura social. Comparten con las víctimas propiciatorias un elemento básico debido al racismo, fenómeno recurrente en la historia de los países latinoamericanos, por el que pueden ser agraviadas con consentimiento de la población en general, lo cual evitaría cualquier progresión de violencia que, lejos de aminorar el conflicto, pudiere avivarlo.

En este sentido, cumplen con la condición sine qua non de las víctimas propiciatorias que reafirma, de otra parte, uno de sus componentes mayores: que son casi humanos. Las víctimas tienen que parecerse en algo a los enemigos, pero no al punto de confundirse con ellos. Así, los genocidios cuentan previamente con el despojo de toda humanidad hacia las víctimas, base de todo racismo.

\section{Genocidio y crímenes de lesa humanidad}

Yo no encuentro otra solución más que exterminarlos o meterlos en reservaciones como en Estados Unidos, es imposible meterle cultura a alguien que no tiene nada en la cabeza [...] son un freno, un peso para

el desarrollo, sería más barato y más rápido exterminarlos.

(Respuesta de un ingeniero industrial de 55 años que se considera "blanco").

El término "genocidio", acuñado por el jurista polaco Raphael Lemkin, se define como la puesta en práctica de acciones coordinadas que tienden a la destrucción de los elementos decisivos de la vida de los grupos nacionales, con finalidad de aniquilamiento. Para Michael Mann (citado por Castrillón, 2009), es el grado más extremo de violencia grupal y el más extremo de todos los actos de limpieza étnica, realizado en determinados contextos y la confluencia de varios factores, como son la falta de legitimidad política o las crisis económicas profundas. Jurídicamente, se considera delito internacional por la Convención para la Prevención y la Sanción del Delito de Genocidio de 1948, así como por el Estatuto de Roma de la Corte Penal Internacional de 1998, y comprende actos perpetrados con intención de destruir total o parcialmente a un grupo nacional, étnico, racial o religioso, como son:

- Matanza de miembros del grupo.

- Lesión grave que afecte la integridad física o mental de los miembros del grupo.

- Sometimiento intencional del grupo a condiciones de existencia que hayan de acarrear su destrucción física, total o parcial. 
- Medidas destinadas a impedir nacimientos en el seno del grupo.

- Traslado forzoso de niños del grupo a otro.

El concepto es declarativo para reconocer, por un lado, la intencionalidad de las acciones. Los genocidios no son acciones inesperadas o aberraciones inexplicables, sino que responden a planes orquestados desde la racionalidad del poder - análisis del poder en términos de tecnología, táctica y estrategia (Foucault, 1976)-, e inscritos en los procesos constructivos los nacionalismos. Por otro lado, si bien el concepto incluye las dimensiones étnico-nacionales y móviles religiosos en la base de los genocidios, el componente racial es el factor determinante para comprender el genocidio en Guatemala.

En primer lugar, es preciso establecer los rayanos fronterizos entre raza y etnia, como una problemática subyacente al discurso antropológico sobre naturaleza y cultura y, desde la sociología política, las derivaciones racistas como ideología de Estados modernos. Si bien el racismo folk, un sistema popular de prejuicios y discriminaciones dirigido contra un grupo, tiene una vieja data, lo interesante es que este tipo de representaciones sociales llegó a tener estatus de dignidad científica.

Antes del siglo XIX no se atisba ningún esfuerzo por probar que la supremacía tecnológica de un pueblo sobre otro era resultado inevitable de las leyes biológicas. La discusión es causa de la teoría darwiniana y el apogeo del positivismo, donde las diferencias físicas entre los seres humanos representan, con componente etnocéntrico, grados de evolución en cuya cúspide estaban los blancos.

La problemática llega a su exacerbación cuando el pensamiento decimonónico establece un vínculo indisoluble entre raza y cultura. Al respecto, Marvin Harris afirma:

Según la doctrina del racismo científico, todas las diferencias y las semejanzas socioculturales de importancia entre las poblaciones humanas son variables dependientes de tendencias y actitudes hereditarias exclusivas de cada grupo (Harris, 1986:70).

El racismo establece, además, una correlación causal entre la herencia biológica como aptitud para crear civilización. La discusión en la antropología adquirió cierto sosiego con la introducción del concepto de "etnia", que reconocía las diferencias culturales de pueblos sin alusión a elementos biológicos o raciales. No obstante, en la construcción del ideal de nación en América Latina, se conformaron como comunidad imaginada con derechos autónomos y una fraternidad de iguales por su procedencia. "La fatalidad compartida del nacimiento fuera de España": una lengua común hablada que tiene como horizonte el arquetipo de las naciones europeas (Anderson, 2007:98) mantuvo el componente racial para explicar las diferencias culturales. Este cuerpo hipotético configuró esquemas de representación social enraizadas en los nacionalismos. 
En la definición de una etnia tuvo más peso el concepto de raza; es más, podemos decir que el concepto de etnia, en alusión a pueblos, se amarró inexorablemente al concepto de raza.

Para Mann, los genocidios en el siglo XX anidan en las conceptualizaciones de la democracia. Las democracias -señala- no están exentas de cometer actos de limpieza étnica, porque encierran la aspiración de homogeneidad étnica en la que "demos" se identifica, paradójicamente, con una etnia en particular, de suerte que la limpieza étnica es el lado oculto de la democracia, porque justifica la tiranía de unos grupos sobre otros y la hace proclive al aniquilamiento de toda diferencia.

Así, el racismo y las limpiezas étnicas se vinculan a una práctica de Estado, en tanto ostentador del monopolio de la violencia, que se arroga la decisión de quiénes merecen vivir. "El racismo desde el Estado [no solamente como] una ideología de la diferencia y de la desigualdad [...], discriminación y opresión entre grupos étnicos, sino como una lógica de exterminio, como tecnología del poder" (Casaús, 2003:25) (Ver Maspoli, 2008).

Las bases filosófica y política de la constitución del Estado moderno poseen un componente bio-racial, llamado por Foucault "biopoder", y es en el racismo donde se encuentran las bases históricas del genocidio, tal como afirma Martha Casaús:

Es en el Estado y sus aparatos represivos en donde el genocidio opera como la máxima expresión del racismo, porque constituye un elemento intrínseco al mismo y forma parte de uno de sus ejes vertebradores utilizados y manipulados por las élites de poder que se consideran blancas (Casaús, 2003:128).

Así, el racismo es una construcción histórico-estructural, un ingrediente de un sistema ideológico en sus aspectos cognitivos para la interpretación de acontecimientos $\mathrm{y}$, por tanto, está en la base de las interacciones sociales. Debido a su naturaleza institucional se ha construido mediante la educación, política, arte o religión y, por ello, es adquirido por la sociedad. Desde allí, las prácticas genocidas extraen su significado en determinados contextos políticos, sociales y económicos.

El genocidio tiene, en este sentido, un carácter masivo, por lo que necesita la colaboración de una estructura social. Explica el accionar directo o el silencio cómplice del grueso de la sociedad para la implementación de sus prácticas.

De alguna manera, los aparatos represivos e ideológicos del Estado operan con mecanismos sutiles, utilizando los discursos y prácticas racistas para desencadenar en la población no indígena odio y violencia, cuando no silencio y complicidad por parte de los ciudadanos (Casaús, 2003), pero también internalizado entre la misma población indígena como factor de distinción. 


\section{Genocidio en Guatemala}

Ríos Montt nos dijo que se acabara con toda esa basura ixil porque colaboran con la guerrilla [...] Los soldados nos gritaron que nosotros los indígenas, no éramos nada, éramos animales, no nos merecíamos el respeto de un ser humano". (Indígena ixil)

La tipificación del delito de genocidio conduce a pensar que en Guatemala no se llevó a cabo sólo contra la población maya, sino que fue el accionar del Estado contra agrupaciones sindicales, asociaciones de trabajadores, la iglesia católica, organizaciones estudiantiles y los mismos militantes de organizaciones de izquierda. Sin embargo, ninguna de estas organizaciones ha reivindicado el término para exigir justicia. Desde la firma de los tratados de paz en 1994, quedó establecido que se habían cometido delitos de genocidio y crímenes contra la humanidad, y una distinción no establecida formalmente entre enemigos ideológico-políticos y víctimas de genocidio. El delito ha quedado, en nuestro razonamiento, circunscrito a móviles de tipo étnico-racial, ante el drama insoslayable y el éxodo de grupos mayas.

En Oslo, en 1994, se firmó el acuerdo para conformar una comisión de la verdad para investigar los crímenes perpetrados, la "Comisión de Esclarecimiento Histórico”. En 1996 se firmó el Acuerdo de Paz Firme y Duradera en Guatemala. Esta Comisión publicó su informe final Memoria del silencio, en 1999. Como parte del proceso de paz apareció la Ley de Reconciliación Nacional, que promulgó una amnistía para los actores de la guerra, pero se excluyeron los crímenes de genocidio, tortura y crímenes de lesa humanidad (Oficina de Derechos Humanos del Arzobispado en Guatemala, 1998).

En la exclusión, por parte de una comisión oficial, se indicaba que por saña, discriminación y carácter selectivo contra un sector de la población, se trataba de un sacrificio orientado por móviles de tipo racial y consolidado mediante la confluencia ideológica con fuerte componente étnico-nacionalista por parte de la oligarquía, la iglesia y el Estado-militar.

El indio como problema, en el entramado de un universo simbólico del Estado liberal corporativo, y los imaginarios en torno al ideal de la nación guatemalteca, construidos desde estereotipos negativos en oposición, lograron calar en el imaginario colectivo. La vigencia de este discurso se inscribe en el andamiaje discursivo de Ríos Montt en dos documentos que sirven como referencia para este trabajo: la conferencia de prensa ofrecida el 2 de junio de 1982, titulada Yo controlo el Ejército, y su declaración en el juicio. Es pertinente identificar, por tanto, la estirpe racista implícita en el genocidio.

Para Casaús (2003, 2007), en la historia de Guatemala se reconocen diferentes posicionamientos de las élites en torno a los pueblos indígenas: 
- La Colonia y tránsito a ideologías democrático-burguesas del liberalismo.

- Crisis de los años sesenta por derrocamiento del presidente Árbenz y clausura de los esfuerzos de renovación social.

- Años ochenta, que culminan en el genocidio durante el gobierno del general Ríos Montt.

La construcción ideológica y política de la Colonia hacia los indios, por parte de blancos europeos, marcada por el racismo, no terminó con la Independencia. La emergencia de nuevos actores sociales, las transformaciones en la tenencia de la tierra que restringieron las tierras comunales y acrecentaron el latifundio, colocaron el problema agrario en el corazón de las reivindicaciones sociales de los pueblos originarios en el siglo $\mathrm{XX}$. El racismo adquiere mayor vigor instrumentalizado directamente desde el Estado con nuevos marcos normativos, ordenanzas laborales, reestructuración político-administrativa e imaginario de las élites gobernantes.

La inclusión o exclusión del indio en la configuración de la nación moderna y el papel que habría de jugar como ciudadano súbdito o bárbaro, se convierte en preocupación central de las élites criollas. Para los esfuerzos integracionistas, el indio es asumido como embrutecido, pero recuperable; por tanto, era una tarea a implementarse vía la educación. Para la transformación del indio, Justo Rufino Barrios emite en 1879 el Decreto 241 para fundar un colegio de civilización indígena. Sin embargo, durante este periodo los indígenas vivenciaron el despojo de sus tierras mediante el Decreto 170. Se autorizó el reparto de las tierras indígenas entre oficiales liberales y grandes extensiones fueron subastadas entre la población alemana avecindada en la Alta Verapaz (Castellanos, 1992). Así, la propiedad comunal dedicada a cultivos de subsistencia y eje rector de la reproducción cultural de los pueblos ancestrales se convirtió en propiedad privada dirigida al cultivo de productos de agroexportación. La gran mayoría de los indígenas pasaron a formar parte la servidumbre de la clase emergente y sólo una minoría ingresaría a colegios para su instrucción. Esto sería muy revelador, casi un siglo después, durante la dictadura de Ríos Montt, cuando un sector minoritario de población indígena, con instrucción y solvencia económica, le dio apoyo contra sus congéneres.

Sin embargo, la vía de integración indígena a la vida política y sociocultural del país será la excepción. El racismo continuó como elemento clave del nuevo Estado oligárquico e, incluso, se tradujo en el debilitamiento de consideraciones jurídicas de las que gozaba esta población en la Colonia.

Durante el siglo XX, el discurso racista se recrudeció con las nuevas formas de dominación capitalista. La conversión de la blancura en autoritarismo político fue la ruta que los liberales guatemaltecos adoptaron, con criterios de 
inmigración selectiva de alemanes y nórdicos para mantener el estado excluyente (Casaús, 2003).

La condición étnica va a ser punta de lanza de la Revolución de 1944. El VI Censo de Población arroja que 75\% de la población guatemalteca vivía en áreas rurales y, de ésta, $62.38 \%$ era indígena que vivía de la agricultura. Por ello, declara punible cualquier tipo de discriminación; prohibió el latifundio y declaró inalienables las tierras ejidales, evitando que los terratenientes recuperaran las parcelas dadas a los campesinos.

Las elecciones de 1950 dan el triunfo a Árbenz, con el apoyo de la clase media, obreros, campesinos y el Partido Guatemalteco del Trabajo. Durante su gobierno se implementó la Reforma Agraria; sin embargo, se vio interrumpida por el golpe de Estado conducido por la operación PB Success, con el respaldo de los EUA, y la gestión local del general Carlos Castillo Armas. Allí se reactivó la exacerbación del racismo y se reanudaron represalias contra la población campesina que cobijaba la Reforma (Giordano et al., 2014).

El racismo fue esgrimido para marcar los rayanos entre el "nosotros" y los "otros", y hacer frente al movimiento popular revolucionario. De 1978 a 1984 se produjo un vacío de poder y una pugna interoligárquica por la hegemonía, todo acompañado por la incorporación masiva de los pueblos mayas a distintas formas de lucha política, a lo que se sumó una crisis económica por agotamiento del modelo exportador, que dio lugar a reacciones agresivas de la élite (Casaús, 2003).

El racismo ha sido también el mecanismo más socorrido de la oligarquía militar ante la falta de legitimidad y una economía dependiente basada en el monocultivo y un modelo agroexportador, sujeto a vaivenes de mercados internacionales. En ese lapso se implementaron los asesinatos selectivos que, desde ese momento, en la confluencia de los factores anteriores y en razón del fortalecimiento de los grupos guerrilleros, auguraban el genocidio de los años ochenta.

Minar los cimientos sociales de los cuales se "alimentaba la guerrilla" fue la razón utilizada para implementar el programa Tierra Arrasada, donde se sabía que la guerrilla había creado bases de apoyo. Esta base social contó con el trabajo previo de organización comunitaria de los años setenta desarrollada por la Iglesia Católica.

Al respecto, se ha indicado que se trataba de "una labor de concientización [que] se desarrolló bajo los principios del bien común y la dignidad de la persona humana". Por ello, desde el inicio, se combinaron las reivindicaciones socioeconómicas con las de tipo étnico. En distintas experiencias se pudo comprobar que la población respondía al tema de la dignidad de la persona humana, evidenciando su sensibilidad frente a las concepciones 
discriminatorias contra los indígenas (Oficina de Derechos Humanos del Arzobispado en Guatemala, 1998:115).

La ideología oligárquica no es estática y también ha pasado por procesos de recomposición, después de su filiación íntima con el catolicismo y el papel de éste en el fortalecimiento económico de la Iglesia, vinculado al régimen latifundista y a la conversión de los indígenas. Sin embargo, durante finales de los años ochenta desarrolló una estrategia antisubversiva que combinó aspectos militares, políticos y religiosos de la "Iglesia del Verbo", de filiación neopentecostal, en la que el presidente de la República era una de las cabezas más visibles:

La llegada de Ríos Montt fue el boom de las sectas neopentecostales y tuvo una especial connotación en la ofensiva contrainsurgente, con el golpe de Ríos Montt comenzó a actuar en el área ixil la Iglesia del Verbo, filial guatemalteca de la iglesia fundamentalista Gospel Outreach con sede en Eureka, California, Estados Unidos. La Iglesia del Verbo, para canalizar estas ayudas, creó la Fundación de Ayuda al Pueblo Indígena (Oficina de Derechos Humanos del Arzobispado en Guatemala, 1998:116).

La alianza militar-oligárquica con tendencia neopentecostal fue una ideología reactiva a un movimiento guerrillero comunista y a la Teología de la Liberación, que convirtió a los indígenas en el pueblo elegido de Dios. Un comunismo religioso se liaba con uno secular que, en todo caso, tenía como fundamento la plataforma de la igualdad entre seres humanos.

Una crisis económica no desata una campaña genocida. Los indígenas aparecen al mismo tiempo redimidos por ideologías seculares y religiosas, ocupan tierras y se fortalece la organización ancestral de los pueblos a raíz del trabajo de muchos párrocos. Es esta organización social la que se convierte en amenaza para la oligarquía guatemalteca y reaviva el sentimiento racial como as bajo la manga. No son el enemigo interno. Esas poblaciones son base de modelos de desarrollo político que el Estado de Guatemala decide sacrificar para estrangular la amenaza real que representan los movimientos guerrilleros.

La estrategia político-militar oligarca se dirige a la base social: "quitar el agua al pez". Es un discurso nacionalista que reivindica la patria contra la amenaza del comunismo soviético y en contra del lastre que representan los indígenas. Sin embargo, el poder se lanza no contra su enemigo políticomilitar directo, la guerrilla, sino contra su base social en el campo: campesinos indígenas, víctimas de daños físico, psicológico, moral, patrimonial y cultural. El sacrificio de los pueblos mayas liquidaba militarmente al "enemigo interno" y cohesionaba el ideal de nación de la sociedad guatemalteca.

\section{Mística del poder y construcción del enemigo interno}

¿Enemigo interno y víctima sacrificial? Para Magda Ahumada abordar el tema del enemigo interno es tanto como internarse en los laberintos del poder; 
es dar cuenta no sólo de una estructura social, sino de la mística del poder. ¿Cómo se construye progresivamente el perfil del enemigo hasta adquirir matices dionisiacos, peligroso, para finalmente liquidarlo con legitimidad? Este componente, reportado como parte del dinamismo de sociedades tradicionales, adquiere mayor potencia en el marco de las sociedades modernas y forma parte de la instrumentación del ejercicio del poder político. En su razonamiento, el "enemigo interno" es un concepto multifacético que ha pasado por diferentes momentos, enmarcado por procesos de confrontación permanente con diferentes matices. Por tanto, el "enemigo interno" es una construcción histórica y política, herencia de la Guerra Fría y vinculado a los territorios nacionales; una amenaza para los grupos de poder.

El enemigo interno (Ahumada, 2007) surge con la identificación del comunismo internacional como enemigo común; amenaza para la seguridad colectiva de los Estados bajo la influencia de los EUA. Posteriormente, toma nuevos significados frente al auge de las revoluciones socialistas y la expansión del pensamiento comunista en Centro y Suramérica, a partir de la cual se trasplantó la Doctrina de Seguridad Nacional como marco para el análisis de las dinámicas sociales en nuestros países, en materia de seguridad. Esto llevó a que la categoría política se definiera desde lo militar y se convirtiera en el centro del accionar de los ejércitos.

Aunque en la formulación de las políticas devenidas de la Conferencia de Paz (Buenos Aires, Argentina) y la Conferencia Panamericana (Lima, Perú, 1938) quedó establecido como "enemigo" quien viole la soberanía del territorio o se inmiscuya en los asuntos internos de un país, con el proceso de la creación de la Escuela de las Américas en Panamá, uno de los centros de formación militar más importantes en América Latina, quedó establecido el vínculo entre comunismo y contrainsurgencia, además de la cooperación entre fuerzas militares multinacionales.

Esta escuela militar, producto de la Guerra Fría, desde su instauración se relaciona con el fortalecimiento de los ejércitos latinoamericanos contra el comunismo y cualquiera de los intentos revolucionarios del continente. "Contrainsurgencia" fue la palabra clave para justificar muchas dictaduras y crímenes en América Latina desde los años sesenta a los ochenta. La población en general y los gremios, movimientos sociales, educadores, organizaciones, sindicatos, trabajadores y líderes estudiantiles se convirtieron en enemigos internos mediante la construcción de un discurso ideológico que desconocía los procesos históricos locales y cualquier demanda social.

El comunismo internacional fue visto como el enemigo común que se infiltraba a través de los movimientos sociales y, por tanto, amenazaba la seguridad de los Estados americanos. Así, se convirtió en instrumento de persecución contra quienes pensaran y se organizaran, dentro de los territorios nacionales, de manera distinta a como permitía la legislación. 
Sin embargo, ante la falta de una intervención abierta, el enemigo externo se presenta dentro del escenario nacional. Le corresponde al Estado y a sus fuerzas militares el debilitamiento de esas organizaciones y la inmovilización de su accionar. En ese sentido, se asume que el Estado detente el monopolio de la fuerza y, aunque esté debilitado, se legitima dentro de la vida nacional la necesidad de apagar a los enemigos internos que lo confrontan, en cumplimiento de la carta constitucional, la defensa del ser colectivo y el mantenimiento del orden establecido.

Estos componentes sientan las bases para identificar la figura del "enemigo interno" entendido como un agresor de la soberanía nacional en cada Estado. En el mismo territorio se identifica como un contendiente contra los intereses de la patria. De esta manera, se constituyó no sólo un enemigo internacional, sino que en cada país se encontraba un "enemigo interno".

Así, quienes reivindicaban la lucha por sus derechos, conformaron para las élites locales el cuerpo social del "enemigo interno." Guatemala no fue la excepción: algunos elementos más negativos de la tradición de Estado en ese país y de la sociedad, como violencia, impunidad, racismo y corrupción, terminaron por convertirse en el sello distintivo de la vida política diaria. Como consecuencia, Guatemala entraría en una espiral de violencia que marcaría la llamada "Época de Lucas."

La estrategia estuvo dirigida a la destrucción de los movimientos populares. El terrorismo fue la respuesta pujante a las luchas abiertas. El gobierno canceló asociaciones de telegrafistas, radiotelegrafistas y de empleados de correos; dirigentes destacados de la oposición socialdemócrata.

También la violencia derivó hacia operaciones de limpieza social. En los primeros seis meses de 1979 fueron asesinadas 1,224 personas señaladas de criminalidad común (Oficina de Derechos Humanos del Arzobispado en Guatemala, 1998:94). Sin embargo, la represión estuvo encaminada al descabezamiento del movimiento popular. Estas acciones se entremezclaban con detenciones policiales a solicitud de los empresarios, con amenazas de organizaciones paramilitares o crímenes y secuestros de dirigentes populares.

En el medio rural, cabe destacar que en marzo de 1979 comenzó el desalojo de campesinos de la región de Chixoy, Baja Verapaz, donde se iba a construir una presa hidroeléctrica. En octubre, doscientos campesinos de la finca Izotal de Sacatepéquez y trabajadores de la fábrica Hilados y Tejidos de San Antonio, de Chimaltenango, ocuparon la iglesia El Calvario. Estas acciones presagiaban las tragedias que comenzarían a generalizarse en los dos años siguientes, especialmente en zonas con actividad guerrillera.

Según el Informe de la Comisión de Derechos Humanos, la ola de represión se prolongó durante 1980 y tomó un carácter masivo que terminó desarticulando las organizaciones sindicales urbanas. El Comité Nacional de Unidad Sindical llamó a derrocar el régimen luquista e instaurar un gobierno 
revolucionario, democrático y popular. En enero de 1980 la policía quemó vivos a 39 campesinos de El Quiché en la Embajada de España, y en el segundo semestre de ese año se iniciaron campañas de asesinatos selectivos de líderes comunitarios rurales, al tiempo que se producía una radicalización de las organizaciones campesinas.

En julio comenzó la ofensiva del ejército sobre el área ixil, con la destrucción de la aldea Cocop, en Nebaj. En agosto, el ejército fusiló a sesenta hombres en la plaza del pueblo de San Juan Cotza, luego de que la guerrilla atacó el destacamento militar. El 20 de julio fue cerrada la diócesis y en agosto una parte de los religiosos abandonaron el país y formaron la Iglesia Guatemalteca en el Exilio (Oficina de Derechos Humanos del Arzobispado en Guatemala, 1998).

El "enemigo interno" era la mayoría de la sociedad guatemalteca en demanda de sus derechos. Los hechos revelan que la ofensiva antiguerrillera había sido preparada sistemáticamente, cuya ejecución inicia durante el gobierno de Lucas Romeo. De enero de 1981 a marzo de 1982 da inicio la ofensiva del ejército en la zona del nororiente de Chimaltenango y sur de El Quiché, como respuesta a que las acciones de propaganda armada que la guerrilla había desarrollado "por primera vez arrojaban saldos estremecedores."

Al comienzo, es probable que estas campañas militares estuvieran dirigidas contra comunidades seleccionadas por su afinidad con la guerrilla y ejecutadas por las autoridades de las zonas militares locales. Esto alcanzaría nuevos derroteros, porque luego la ejecución del programa militar represivo estuvo a cargo el Estado Mayor General.

La inercia de masacres se prolongó, adquiriendo cada vez un carácter más dramático en la escalada ofensiva contra la guerrilla. En El Quiché y el noroeste de Chimaltenango, en Baja Verapaz, Ixcan, Huhuetenango, Petén y en la Costa Sur se observa la tendencia de campañas represivas ejecutadas por el mando de la Zona Militar, en ocasiones con la colaboración de bandas paramilitares.

Aparte de las víctimas civiles, el ejército centró su atención en eliminar las bases de apoyo a la guerrilla en zonas del enfrentamiento militar, o donde la guerrilla había creado bases de apoyo. En ese sentido, tanto la campaña de asesinatos individuales como la de crímenes colectivos continuó en otras zonas del país, cada vez más dirigidas por el Estado Mayor General, pero bajo responsabilidad operativa del comandante de la zona militar.

El segundo semestre de 1980, el Estado Mayor General inició con su propio plan de contrainsurgencia en el campo. En las primeras etapas de represión selectiva recurrió a comisionados militares, informantes y autoridades locales, muchos de los cuales tenían sus propios intereses económicos. Cuando se inició la represión selectiva en el campo, numerosos empresarios agrícolas que 
ocupaban cargos de comisionados militares o tenían sus propios equipos de seguridad colaboraron con el ejército en el asesinato de líderes campesinos, especialmente en las áreas de conflicto, prestando avionetas para que fueran artilladas y usadas para el bombardeo: "Llegaban a los cuarteles, nos exigían mano dura [...], se creían autoridad” (Oficina de Derechos Humanos del Arzobispado en Guatemala, 1998:108).

Esta política de represión selectiva configuró una especie de estética de la escalada violenta desde cada uno de los actores, recurriendo al terror exhibido como recurso disuasivo, especialmente ante el avance de las acciones de la guerrilla.

Según el informe de la Comisión para el Esclarecimiento Histórico, en 1981 la guerrilla se proponía declarar como "territorios liberados" una porción del suelo patrio para darles a sus miembros categoría de "beligerantes", estrategia con la cual aspiraban a tener acceso a los foros internacionales y reconocimiento por parte de los principales países afines. Por tanto, sus primeras acciones estuvieron encaminadas a eliminar el poder local, recurriendo al secuestro y desaparición de alcaldes auxiliares, alcaldes municipales y comisionados; afectar la economía nacional mediante asesinatos, asaltos, quema de fincas, destrucción de cultivos e infraestructura y bloqueo de carreteras.

El involucramiento de la población le confería legitimidad al esfuerzo insurgente $\mathrm{y}$, sumado al control territorial, podía conducir a que internacionalmente se le considerara "fuerza beligerante", tal cual había ocurrido en 1981 con el Frente Farabundo Martí para la Liberación Nacional salvadoreño, mediante la Declaración Franco-Mexicana.

Fue así como, en los últimos meses del gobierno de Lucas García, el Estado Mayor General diseñó una estrategia contrainsurgente que alcanzaría su integralidad después del golpe de Estado del 23 de marzo de 1982.

La zona de asentamiento guerrillero en el triángulo Ixil era estratégica: poca densidad de población indígena confinada que la hacía proclive a los ideales políticos de la guerrilla; además, con poca presencia del Estado. Espacio propicio de ser declarado territorio libre para reconocimiento de beligerantes. Esta situación la reitera Ríos Montt en su juicio:

... querían que se declarara que aquí había una guerra interna para declarar territorios libres [...] Lo cierto del caso es que se logró parar la ambición guerrillera. No pararla porque ellos siguieron y siguen [...] y están de tal manera capacitados de seguir trabajando con otros medios porque seguían la idea de Mao Tse-Tung, que la paz es la guerra con otros medios (Ríos Montt, 2013, declaración en video).

Si bien los planes Victoria 82, Firmeza 83 y Operación Sofía fueron operativos militares en los que se llevó a cabo el genocidio contra el pueblo ixil, hay que reconocer que también había esfuerzos por atraer a la población 
al Ejército para contrarrestar las acciones de la guerrilla. Se establecieron los programas contrainsurgentes Fusiles y Frijoles y Techo; Tortillas y Trabajo. Al respecto escribe Ricardo Falla:

El factor psicosocial, definido por el ejército en marzo de 1982 como uno de los cuatro elementos necesarios para el logro de la pacificación, reconocía la necesidad de integración de los grupos indígenas a la nacionalidad guatemalteca. Pero la respuesta que dio el ejército no fue psicosocial, sino militar exclusivamente. Esta respuesta militar por la deficiencia del elemento psicosocial, fue precisamente una discriminación que llegó al extremo, es decir a la muerte del despreciado e infravalorado (Falla, 1990:165).

El control de la población, por parte de ambos contendientes, era capital para determinar el desenlace de la guerra a favor de uno u otro. La ofensiva final desemboca en el genocidio del pueblo ixil.

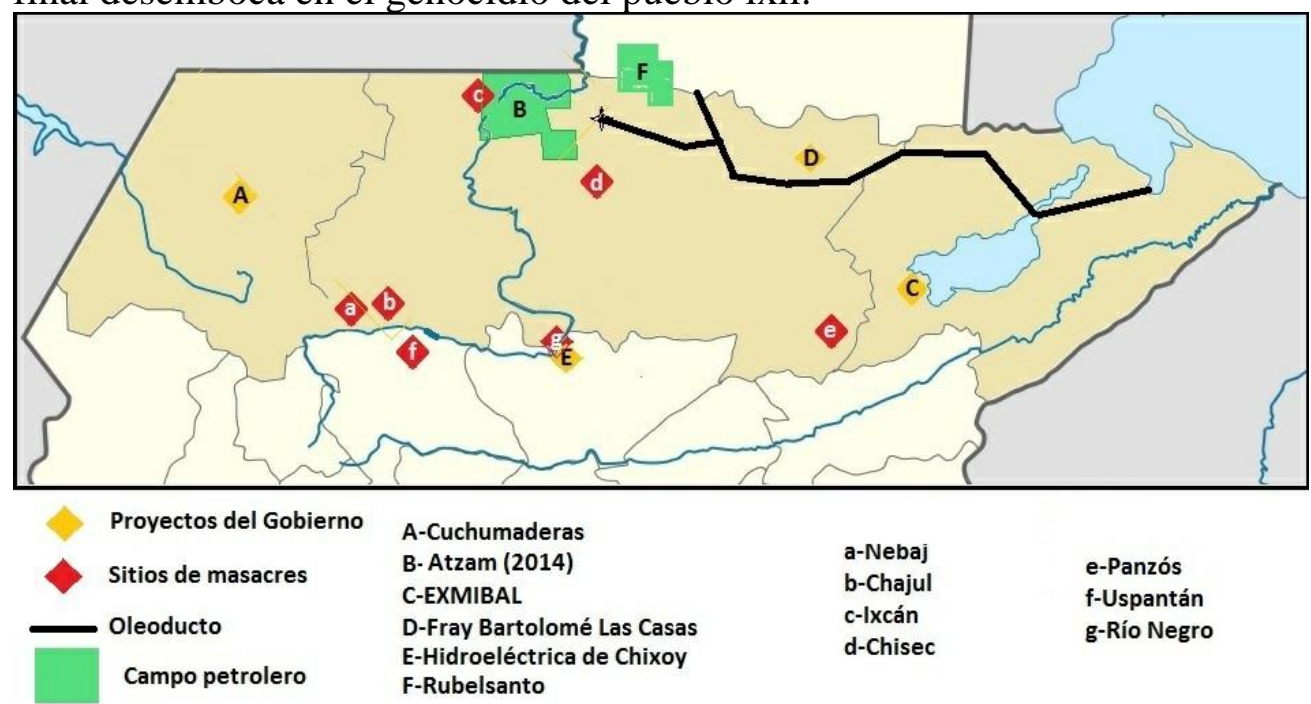

Figura 1. Relación entre proyectos de gobiernos y sitios de masacres en la Franja Transversal del Norte. Fuente:

https://es.wikipedia.org/wiki/Guerra_Civil_de_Guatemala\#/media/File:FTNprojects.jpg 


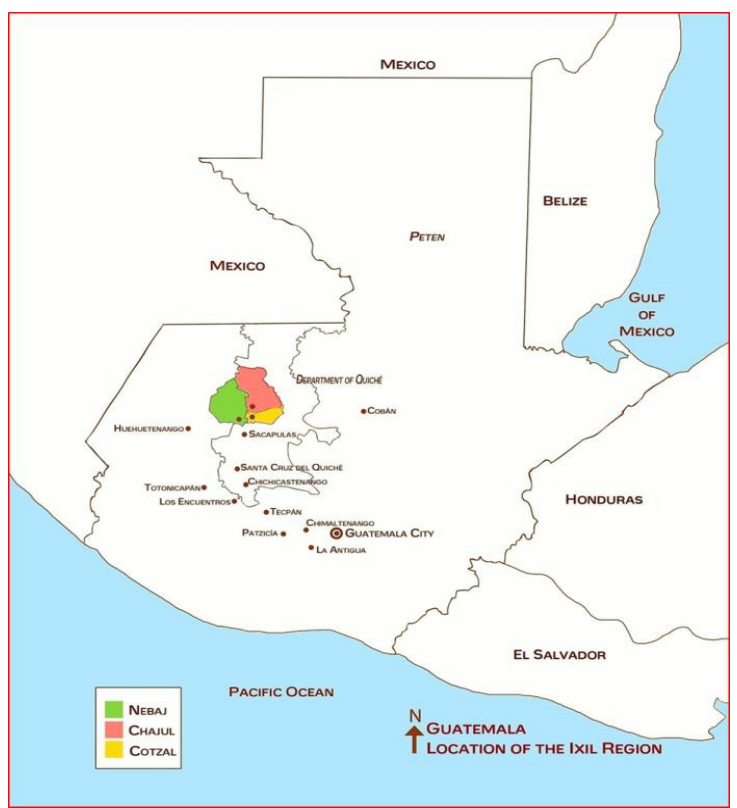

Figura 2.Territorio ancestral de los maya-ixil.

Fuente: Territorio ancestral del pueblo ixil. Mapa de Susan Badgley.

La mayor concentración de masacres registradas por la Comisión del Esclarecimiento

Histórico, durante los 35 años de guerra civil, trazada sobre el mapa etnolingüístico de

Guatemala. La zona de mayor intensidad coincide con el territorio ancestral de los maya-

ixil:

http://www.centralamericanstories.com/es/characters/sebastian/

\section{¿Por qué el pueblo ixil?}

Esta pregunta ha orientado nuestra reflexión y es la misma que ha interpelado a otros investigadores, quienes han respondido con tres tesis: a) la oficial: la violencia en la región ixil intentaba socavar las bases sociales de la guerrilla, que había ganado adeptos.

Las otras dos, más de carácter académico, sostienen que: b) a la región ixil, la guerrilla tenía posibilidades de declararlo territorio independiente $y$, por tanto, ganar reconocimiento internacional del movimiento armado, y c) la zona ixil tiene rezagos y en ella es débil la autoridad del Estado.

En realidad, las tres conjeturas se retroalimentan. La represión en la región ixil no fue resultado de fricciones entre grupos locales, sino que fue elegida por ser "atrasada", con presencia débil del Estado y "la reacción previsible del Estado podría ayudar a la guerrilla a montar su movimiento", señala David Stoll (1999:93).

Las tesis anteriores fundamentan nuestro razonamiento sobre los ixiles como víctimas sacrificiales, no sólo por parte del Ejército, sino incluso por el Ejército Guerrillero de los Pobres, que colocaba a la población como objeto de represalias. Joel Simon afirma: "La táctica del EGP, que más tarde hizo suya el ejército, era crear un clima en el cual la neutralidad fuera imposible" 
(Citado en Stoll, 1999:103). La agudización de las contradicciones, como motor del programa de liberación nacional del Ejército Guerrillero de los Pobres, contaba con siglos de frustración por parte de la población ixil, y que la represión engrosaría las filas de sus milicianos.

Qué tanto de todo esto responde a un cálculo donde la población indígena era parte de saldo de la guerra, no puede afirmarse, pero partimos de la idea extendida en el imaginario racista como consenso de todos los blancos, ladinos y mestizos de Guatemala que conformaban los rangos medios y altos, lo mismo en el ejército que en la guerrilla.

Si bien las "naciones", como refiere Ríos Montt, en referencia a los grupos étnicos maya q'eqchi, mam, kajobal, kachikel fueron atacadas, en su mayoría lograron salvar la vida debido a la situación geográfica que les permitió a cruzar la frontera mexicana. No sucedió lo mismo con los habitantes mayas del triángulo Ixil para quienes, como afirma Stoll "el fango, la selva y los ríos al norte de la zona ixil, les impedían cruzar la frontera" (1999:169).

Los ixil quedaron atrapados entre dos bandos: guerrilla y ejército. Originalmente, los ixil se unieron como combatientes al Ejército Guerrillero de los Pobres. Cuando la primera fuerza de éste incursionó en la parte sur de El Quiché, una proporción de la población ya la estaba esperando. Los combatientes se sorprendieron por la acogida multitudinaria y la rapidez con la cual la población se organizaba, de acuerdo al modelo guerrillero.

Esto, como resultado de la acción católica e iniciativas impulsadas por párrocos, que hicieron una concientización desarrollada bajo los principios de la dignidad humana. Por ello, se combinaron las reivindicaciones socioeconómicas con las de tipo étnico (Oficina de Derechos Humanos del Arzobispado en Guatemala, 1998:117).

La región, considerada bastión de la guerrilla, se convirtió en un eslabón de las "Aldeas Modelo". El Ejército controlaba la mayor parte de la zona bajo un esquema de contrainsurgencia, consistente en asentamientos obligados a utilizar salvoconductos para moverse en el área, patrullas obligatorias e incursiones militares.

Entre 1978 y 1979 la lucha guerrillera se extendió por el país con el surgimiento de nuevos grupos que golpeaban al sector empresarial agrícola. En la zona ixil se adentraban en una lucha por el control del poder local y su estrategia fue la guerra de guerrillas. El escenario de combate se desarrolló al norte de El Quiché.

La guerrilla se intensificó en la capital y en las zonas rurales fortificó la propaganda armada. En el área ixil, el Ejército Guerrillero de los Pobres organizó una columna guerrillera y se propuso la destrucción de instalaciones del ejército. Como respuesta la fuerza armada ubicó la región como área donde aquel podía declarar un territorio liberado. 
La colaboración indígena con la guerrilla en operativos generó un triunfalismo guerrillero, pero en muchas regiones los dirigentes, sin preparación ni vínculos con organizaciones insurgentes, convirtieron a la población en flanco fácil del ejército y alentaron la deslealtad de algunos jefes del lugar, quienes se erigieron en caciques locales, adoptando un comportamiento bandolero (Oficina de Derechos Humanos del Arzobispado en Guatemala, 1998:117).

Por su parte, la guerrilla atrajo a la gente haciéndola partícipe de sus actividades. La represalia siguiente a cualquier actividad guerrillera fue dirigida no a la guerrilla, sino a la población civil. La intención consistía no tanto en hacer que la gente rechazara cualquier relación con la guerrilla, sino lograr que la misma guerrilla se abstuviera de actuar antes de hacer correr a la gente el riesgo de sufrir tanto barbarismo (Stoll, 1999).

El ejército y guerrilla habían desarrollado una estrategia más segura y efectiva que el enfrentamiento directo.

En cuanto al ejército, de acuerdo a La comisión para el Esclarecimiento Histórico (CHE) la estrategia siguiente se enfocó a controlar la población, sometiéndola a un proceso para obtener documentación que los acreditara como población neutral. Sin embargo, la medida fracasó, pues la mayoría de la población no aceptó el proceso de cédulas para identificarse. El paso siguiente de la ofensiva fue un ataque directo sobre una población que carecía de medios para defenderse. La destrucción de caseríos y cultivos obligó a la gente a abandonar sus tierras y a errar por las montañas. Luego empezaron las masacres.

La represión del ejército cambió la correlación de fuerzas en el área mediante el desplazamiento forzoso, y también a que existían núcleos de población no unidos a la guerrilla que, posteriormente al reconocer recompensa por su apoyo al ejército, se agregaron a la represión. También hubo quienes cambiaron de bando y otros que fueron reclutados forzadamente; de esa manera se conformaron las Patrullas de Autodefensa.

La ofensiva militar del ejército produjo desplazados internos. Ríos de pobladores quedaron en el monte sin tener a dónde regresar ni dónde sembrar. Este drama humano también consolidó la recuperación del territorio por el ejército, y trasladó a la guerrilla la tarea de responder a las necesidades de defensa y sobrevivencia de la población.

Lejos de ser atendidos semejantes retos, la población quedó aislada en la indefensión. Las acciones militares se dirigieron al exterminio de la etnia ixil. Una sobreviviente, testigo durante el juicio, explicó que había escuchado a un soldado decir: "Ríos Montt nos dijo que acabaran con toda esa basura ixil porque colaboraban con la guerrilla" (declaración en video).

La violación sexual a mujeres, como arma de guerra, fue una práctica que incluyó violaciones a menores y a embarazadas. 
Cada vez las masacres cobraban más las características de banquetes sacrificiales: infanticidios, secuestro de niños para darlos en adopción, asesinatos de niños de tres meses por ahogamiento, azotar la cabeza de los bebés contra la pared, arrojarles piedras para destriparles la cabeza, abrir el pecho de las mujeres para sacarles el corazón, abrir el vientre de las mujeres embarazadas, cortar la cabeza de las víctimas para después jugar con ellas "a la pelota".

Una barbarie con el fin pedagógico de neutralizar cualquier intento de adhesión a la guerrilla y lograr apego a las filas del ejército. Los ixiles fueron víctimas sacrificiales, cuyos asesinatos se convirtieron en enseñanza y terror para los demás.

\section{Conclusion}

Lo expuesto en este ensayo constituye, por un lado, un esfuerzo por reafirmar dos tesis en el campo de las ciencias sociales en relación al tema del genocidio. Primera, la que alude al componente racial como constitutivo de las naciones modernas, debido a que están enraizadas en la construcción imaginaria de una confraternidad de iguales, lo que explica el esfuerzo de la estandarización racial y cultural. No obstante, esa mismidad se ha construido en América Latina en oposición a los pueblos ancestrales; una diferencia estigmatizada y violentada por parte de los grupos hegemónicos de fenotipo blanco.

Segunda, la que fortalece la perspectiva del racismo como un elemento fundamental en el genocidio contra la población maya-ixil. El racismo como imaginario construido histórico y de manera sistemática desde el poder y transversal en los esquemas de representación e interpretación de la realidad de la sociedad guatemalteca. Ello explica en gran medida no sólo el genocidio como estrategia político-militar, sino la indiferencia y silencio cómplice de la mayoría de la sociedad guatemalteca frente a la campaña de exterminio de las comunidades maya.

Por otro lado, el segundo esfuerzo de este trabajo consiste en demostrar la tesis de los grupos indígenas maya-ixil como víctimas sacrificiales, en razón de la vulnerabilidad y su extenuación histórica. Reafirma la vigencia de poblaciones confinadas, como bancos de reserva, de poblaciones desechables a cuyo sacrificio recurren los Estados modernos y seculares en situaciones de apremios políticos y económicos.

Afirma que a una estrategia de este tipo recurrió el gobierno de Ríos Montt en razón del racismo histórico para quitarle el agua al pez. A través de la implementación de prácticas militares de exterminio contra la población ixil, el gobierno del exdictador logró crear una eficaz pedagogía del terror mediante la cual lograron desalentar la adhesión de las poblaciones indígenas a la guerrilla, "el enemigo interno". 
El sacrificio de esta población logró desviar y evitó el enfrentamiento entre los enemigos directos: la guerrilla y el ejército. Desde esta perspectiva, el presente trabajo sostiene una propuesta que disiente de la mayoría de los estudiosos en la temática, para quienes los indígenas maya-ixil fueron liquidados porque se consideraron enemigos internos del sistema. Reitera que los genocidios de pueblos ancestrales son una posibilidad latente y consustancial a la división del mundo en Estados nacionales.

\section{References:}

1. Anderson, B. (2007). Comunidades imaginadas. Reflexiones sobre el origen y la difusión del nacionalismo. México: CFE.

2. Ahumada, M. A. (2007). El enemigo interno en Colombia. Recuperado de https://www.google.com.mx/webhp?sourceid=chromeinstant\&ion $=1 \&$ espv $=2 \&$ ie $=$ UTF8\#q=enemigo+interno+antropolog $\% \mathrm{C} 3 \% \mathrm{ADa}$

3. Benhabib, S. (2009). International Law and Human Plurality in the Shadow of Totalitarianism: Hannah Arendt and Raphael Lemkin. Constellations, 16(2), 331-350.

4. Cárdenas, E. (2011). Esos históricos infatigables: dinámicas migratorias de guatemaltecos en el estado de Quintana Roo 19842009. México: Plaza y Valdés Editores.

5. Casaús, M. (2003). La metamorfosis del racismo en Guatemala. Guatemala: Fundación Cholsamaj.

6. Casaús, M. (2007). Guatemala: linaje y racismo. Guatemala: F\&G Editores.

7. Casaús, M. y Dávila, A. (Coords.) (2007). Diagnóstico del racismo en Guatemala. Investigación interdisciplinaria y participativa para una política integral por la convivencia y la eliminación del racismo (Vol. 3). Guatemala: Vicepresidencia de la República.

8. Casaús, M. (2009). El Genocidio, la máxima expresión del racismo en Guatemala: una interpretación histórica y una reflexión. Nuevo Mundo, Mundos Nuevos. Recuperado de https://nuevomundo.revues.org/57067\#tocfrom1n3

9. Castellanos, J. (1992). Tendencias del desarrollo agrario en el siglo XIX. Surgimiento de la propiedad capitalista en Guatemala. Flacso. Recuperado de http://www.flacsoandes.edu.ec/libros/digital/53107.pdf

10. Castrillón, A. (2009). El lado oscuro de la democracia. Un estudio sobre la limpieza étnica, Michael Mann. Democracias, imperialismo, guerras y genocidio: Universitat de Valencia. Recuperado de http://www.economiainstitucional.com/pdf/No22/acastrillon22.pdf

11. Comisión para el Esclarecimiento Histórico (1994), Guatemala. 
12. Falla, R. (1990). Quiché rebelde. Guatemala: Editorial Universitaria.

13. Federación Internacional de Derechos Humanos (2013). Genocidio en Guatemala: Ríos Montt culpable. Declaración de un indígena ixil en el juicio contra Ríos Montt. Recuperado de https://www.fidh.org/IMG/pdf/informe_guatemala613esp2013.pdf

14. Foucault, M. (1976). Genealogía del racismo. Recuperado de http://geopolitica.iiec.unam.mx/sites/geopolitica.iiec.unam.mx/files/S EM0

15. Giordano, V., Nercesian, I. Rostica, J. C. y Soler, L. (2014). Sociedad rural y violencia política en América Latina. Perspectivas comparadas (ca 1950-1970). En Ansaldi, W, y Giordano, V. (Coord.) América Latina, tiempos de violencias (pp. 101-130). Buenos Aires: Ariel.

16. Girard, René (1995). La violencia y lo sagrado. Barcelona: Anagrama.

17. Harris, M. (1986). El desarrollo de la teoría antropológica. Historia de las teorías de la cultura. México: Siglo XXI.

18. JusticeRepublic(2013). Yo controlo el Ejército (1982- 1983). Entrevista a J. $\quad$ E. Ríos

De:https://www.youtube.com/watch?v=PT2tYCvIgUI

19. Maspoli, E. (2008) [Reseña sobre] Daniel Feierstein, El genocidio como práctica social. Entre el nazismo y la experiencia argentina. Recuperado http://www.memoria.fahce.unlp.edu.ar/art_revistas/pr.3734/pr.3734.p df

20. Oficina de Derechos Humanos del Arzobispado de Guatemala (1998). Guatemala: nunca más (Informe del Proyecto Interdiocesano Recuperación de la Memoria Histórica. Tomo 3. (El entorno histórico). Guatemala: ODHAG.

21. Prensa Comunitaria (2013). Peritaje Racismo-Genocidio. De: http://comunitariapress.blogspot.mx/2013/04/peritaje-sobre-racismoy-genocidio.html

22. Prensa Libre tv (2013), Juicio por genocidio contra Efraín Ríos Montt y Mauricio Rodríguez Sánchez, 9 de mayo. De: https://www.youtube.com/watch?v=ka4-J48Ja2w

23. Saroyan, W. Armenia. Stoll, D. (1999). Entre dos fuegos. En los pueblos ixiles de Guatemala. Quito: Ediciones Abya-Yala.

24. TheOkarla(2011).Polifonía de la memoria. Documental. De: https://www.youtube.com/results?search_query=polifon\%C3\%ADa+ de+la+memoria 